\title{
O Gerenciamento de Resíduos Sólidos, Efluentes Líquidos e da Fauna Sinantrópica Nociva no Porto de Fortaleza.
}

\author{
The Management of Solid Waste, Liquid Waste and Noxious Synanthropic Fauna in the Harbor Fortress. \\ Ivan de Oliveira'; Maria Oziléa Bezerra Menezes²; Luis Parente Maia ${ }^{3}$ \\ ' Instituto de Ciências do Mar-LABOMAR, Universidade Federal do Ceará, Brasil \\ ${ }^{2,3}$ Professor(a), Universidade Federal do Ceará, Brasil
}

\begin{abstract}
Resumo
O artigo tem como objetivo o diagnóstico da gestão portuária e socioambiental do Porto de Fortaleza, traçar o seu perfil e propor ações de melhoria para o gerenciamento dos resíduos sólidos, dos efluentes líquidos e da fauna sinantrópica nociva. Os dados foram coletados junto as autoridades portuárias, autoridades intervenientes e os arrendatários. Foi realizado um mapeamento do Porto de Fortaleza, e em seguida a aplicação de questionários e levantamento de dados primários (in loco) por alunos e professores do Instituto de Ciências do Mar LABOMAR, da Universidade Federal do Ceará. A pesquisa identificou da necessidade urgente de um Plano de Gerenciamento estabelecido entre a autoridade portuária, autoridades intervenientes e os arrendatários no sentido de que os resíduos sólidos, efluentes líquidos e fauna sinantrópica nociva, observados no Porto de Fortaleza, sejam devidamente minimizados possibilitando, dessa forma, uma gestão mais segura.
\end{abstract}

Palavras-chave: Gestão Portuária; Porto de Fortaleza; Diagnóstico.

\begin{abstract}
The article aims to diagnose the port environmental management of the Port of Fortaleza, chart its profile and propose improvement actions for the management of solid waste, liquid waste and noxious synanthropic fauna. Data were collected from port authorities, stakeholders authorities and tenants. A mapping of the Port of Fortaleza was performed, and then the questionnaires and collection of primary data (in situ) by students and faculty of the Institute of Marine Sciences - LABOMAR, Federal University of Ceará. The research identified the urgent need for a Management Plan established between the port authority, intervening authorities and tenants in the sense that the solid wastes, liquid effluents and noxious synanthropic fauna observed at the Port of Fortaleza are properly minimized allowing thus, safer management.
\end{abstract}

Keywords: Port Management; Port of Fortaleza, Diagnosis. 


\section{INTRODUÇÃO}

O artigo apresenta um panorama da geração de resíduos sólidos e efluentes líquidos e da presença de fauna sinantrópica nociva no Porto de Fortaleza, Estado do Ceará.

O estudo resulta da preocupação da Secretaria de Portos da Presidência da República - SEP/ PR, com a melhoria das atividades portuárias e com as questões ambientais, de modo a atender as exigências no tocante ao gerenciamento de resíduos sólidos, efluentes líquidos e fauna sinantrópica nociva nas dependências dos portos marítimos brasileiros.

O Art. $1^{\circ}$ da Lei 12.305, de 2 de agosto de 2010, Lei da Política Nacional de Resíduos Sólidos, estabelece sobre as diretrizes relativas à gestão integrada e ao gerenciamento de resíduos sólidos, incluindo os perigosos, às responsabilidades dos geradores e do poder público e aos instrumentos econômicos aplicáveis.

Portanto, o objetivo principal deste estudo consiste no levantamento, tratamento, análise de dados e estruturação da informação, assim como o gerenciamento logístico das operações de campo para o diagnóstico dos resíduos sólidos, dos efluentes líquidos e da fauna sinantrópica nociva (Espécimes de animais vetores ou reservatórios de doenças de importância em saúde pública) no Porto do Mucuripe, em Fortaleza.

Quanto ao objetivo específico estabeleceu-se aferir a quantidade e classificação dos resíduos sólidos; levantar dados primários dos resíduos de bordo das embarcações aportadas no porto; aferir a quantidade de resíduos dispersos no carregamento e descarregamento de material dos navios; acompanhar a retirada de resíduos das arrendatárias/áreas públicas; levantar dados primários dos efluentes líquidos e oleosos; levantar dados da fauna sinantrópica nociva

\section{I Caracterização do porto}

O Porto de Fortaleza está localizado na cidade de Fortaleza, capital do estado do Ceará, nas coordenadas geográficas aproximadas de latitude $3^{\circ} 43^{\prime} 28^{\prime \prime}$ S e longitude $38^{\circ} 28^{\prime} 29^{\prime \prime}$ 'W. Possui uma área aproximada de $0,2 \mathrm{~km}^{2}$, e se situa na enseada do Mucuripe, entre as praias do Futuro e do Meireles, mais especificamente no bairro denominado Cais do porto.

\section{2 ZONEAMENTO E ATIVIDADES ECONÔMICAS}

O zoneamento do porto foi realizado durante as visitas de campo pela equipe do LABOMAR/ UFC. Seguindo a metodologia de trabalho desenvolvida pela equipe, os portos foram divididos em Zonas Portuárias e cada uma das Zonas subdivididas em Perímetros, de acordo com as características administrativas, operacionais e físicas de cada área. No caso do Porto de Fortaleza foi delimitada uma única Zona Portuária, subdividida em doze (12) Perímetros. Cada perímetro delimita um terminal, empresa ou área operacional. E cada área delimitada está relacionada a uma atividade econômica e ou administração específica.

\section{METODOLOGIA}

Trata-se de uma pesquisa prática "ligada à práxis", ou seja, à prática histórica em termos de conhecimento científico para fins explícitos de intervenção.

Quanto aos procedimentos técnicos adotados, ou seja para fins de coleta de dados, classificamos em pesquisa bibliográfica, pesquisa documental e estudo de caso.

As atividades de levantamento de dados in loco foram desenvolvidas por uma equipe multidisciplinar, composta por alunos e professores da Universidade Federal do Ceará (UFC).

Para facilitar a coleta de dados a equipe do LABOMAR/UFC estabeleceu a seguinte divisão: coleta de informações através de levantamento de documentação e através de aferições em campo. A documentação avaliada consistiu nos inventários de resíduos sólidos, manifestos de transporte para resíduos de embarcação, inclusive os oleosos, fossas, e esgoto sanitário e o plano de resíduos sólidos (PGRS) da Autoridade Portuária. No segundo momento, os dados obtidos com a documentação foram validados com aferições in loco, nos últimos pontos de armazenamento dos resíduos dentro da área portuária. 
Atividades econômicas dos terminais do porto de Fortaleza/CE.

\begin{tabular}{|c|c|c|}
\hline Perímetro & Terminal & Atividade Econômica \\
\hline P1 & Armazéns 1 e 2 & Armazenamento de granéis sólidos (grãos). \\
\hline P2 & Cais 1 & Manutenção de máquinas. \\
\hline P3 & $\begin{array}{l}\text { Sede da Cia. Docas, } \\
\text { CODINF, OGMO e } \\
\text { Entrada de } \\
\text { Passageiros. }\end{array}$ & Área Administrativa \\
\hline $\mathrm{P} 4$ & Almoxarifado/OGMO & Área administrativa. \\
\hline P5 & CVT e NAP & Área Administrativa \\
\hline P6 & Pátio de Contêineres & Movimentação de Contêineres. \\
\hline P7 & $\begin{array}{c}\text { Autoclave, Carga } \\
\text { Perigosa (em espera } \\
\text { pela licença } \\
\text { ambiental) }\end{array}$ & $\begin{array}{l}\text { Área Destinada ao Armazenamento de } \\
\text { Cargas Perigosas }\end{array}$ \\
\hline P8 & $\begin{array}{l}\text { Armazém } 3 \text { e } 4 \text { e } \\
\text { Armazém Provisório }\end{array}$ & Armazenamento de Cargas \\
\hline P9 & Cais 2, Pier. & Movimentação de Cargas e Passageiros \\
\hline P10 & Armazém 5 & Armazenamento de Cargas. \\
\hline $\mathrm{P} 11$ & $\begin{array}{l}\text { CDA/HDG e } \\
\text { Transpetro }\end{array}$ & Resíduos Classe I \\
\hline P12 & Vecol e Depom & Área Administrativa \\
\hline
\end{tabular}

\section{RESULTADOS E DISCUSSÕES}

\section{I Resíduos sólidos}

Os resíduos retirados nas áreas do Porto de Fortaleza foram todos declarados em unidade de massa. A partir do levantamento de dados, foi possível observar que $799.367 \mathrm{~kg}$ de resíduos sólidos foram retirados de janeiro a novembro de 2012.

Quando analisados os tipos de resíduos sólidos gerados, foram consideradas três classes: Resíduos Perigosos, Resíduos Recicláveis e Lixo Comum.

\section{I.I Lixo comum}

Do total de resíduos analisados no Porto de Fortaleza, 95,22\% são de lixo comum.

O resíduo comum gerado nas áreas do porto, arrendada e não arrendada, são misturados e retirados juntamente, o que indica para uma não conformidade do porto com relação a coleta seletiva e/ou a segregação dos resíduos gerados. Observa-se, ainda, a inexistência de um programa de coleta seletiva amplamente difundido.

A inexistência contratual com cooperativas ou outras formas de associação de catadores permiti-nos inferir que os resíduos produzidos no porto, passíveis de reutilização e/ou reciclagem, não o são.

Os resíduos gerados são submetidos ao controle da Guia de Controle de Resíduos para serem retirados de dentro do porto, entretanto, o referido documento não especifica a sua tipologia, exigindo 
somente a quantidade em massa, sendo impossível classifica-los.

Quanto aos resíduos da construção civil (RCC), por serem gerados em atividades pontuais, como reformas e construção de edificações, foram contabilizados em separado da geração dos outros resíduos. A quantidade de resíduos de construção civil gerada nos meses de março, setembro, outubro e novembro foi de $26.240 \mathrm{~kg}$.

\section{I.2 Resíduos perigosos}

A classe de resíduos perigosos, no Porto de Fortaleza, é composta por borra oleosa, latas de tinta, resíduos contaminados com óleo e/ou produtos químicos e material elétrico/eletrônico. Estes resíduos foram declarados em quantitativo de $36.620 \mathrm{~kg}$, o que representa, dentro das classes adotadas, 4,74 \%.

\section{I.3 Resíduos ReCICLÁveis}

Já os resíduos recicláveis gerados são compostos por bombonas de plástico não contaminadas e vidro. Estes resíduos foram declarados em quantitativo de $304 \mathrm{~kg}$, o que representa, dentro das classes adotadas, o valor de $0,04 \%$, e isto torna evidente que qualquer tipo de atividade relacionada à seleção e separação de resíduos no porto para posterior reciclagem é insuficiente.

Ressalta-se que a massa que compõe os resíduos sólidos identificados no porto de Fortaleza é potencialmente passível de coleta seletiva, segregação e reuso

Portanto, a gestão portuária não está cumprindo o Art. $6^{\mathrm{a}}$ item VIII, dos princípios e objetivos da Lei 12.305, quanto "ao reconhecimento do resíduo sólido reutilizável e reciclável como um bem econômico e de valor social, gerador de trabalho e renda e promotor de cidadania"

Desta forma, foi possível constatar que:

I. Todo o resíduo gerado nas áreas arrendadas é misturado e retirado juntamente aos resíduos gerados na área não arrendada.

II. Não há exigência contratual para que seja efetivamente feita a coleta seletiva dentro do porto por parte da empresa autorizada a coletar os resíduos.

III. Não existe central de resíduos no Porto de Fortaleza de forma a atender a legislação vigente. IV. Não existe um programa de coleta seletiva amplamente difundido no Porto de Fortaleza. V. Não é feito adequadamente a mitigação da geração de resíduos nas operações portuárias. VI. Não há descrição quanto ao tipo de resíduo na Guia de Controle de Resíduos.

VII. Existem pontos de acumulo de lixo ao longo de todo o porto e que não é retirado regularmente.

VIII. Não existe uma equipe de varrição no sentido de minimizar o acúmulo de resíduos ao longo das áreas do porto.

IX. Não existe um contrato efetivo com associações de catadores para possibilitar a reciclagem e reutilização de resíduos.

\section{RESÍDUOS DE EMBARCAÇÕES}

Os resíduos retirados de embarcação foram registrados em $\mathrm{kg} \mathrm{e} \mathrm{m}^{3}$. A fonte dos mesmos foram os Guias de Controle de Resíduos, exigidos pela Cia. Docas do Ceará (CDC).

A retirada de resíduos de embarcação apontou valores totais de 778,80 $\mathrm{m}^{3}$ e $15 \mathrm{~kg}$. Por isso, da mesma forma que para os resíduos gerados nas áreas arrendadas e não arrendadas, os resíduos de embarcação foram separados em classes: resíduos perigosos, recicláveis e lixo comum.

Importante observar que tal qual os resíduos sólidos, os das embarcações são misturados e retirados diretamente por transporte especializado

Os resíduos recicláveis são compostos por: heterogêneos compatíveis para reciclagem (papel, papelão e plástico) e vidro.

Os resíduos perigosos apresentaram o quantitativo de $9 \mathrm{~m}^{3}$, e foram compostos por materiais têxteis contaminados (máscaras, luvas, roupas, etc.) Já os recicláveis retirados de embarcação apresentaram valores de $65 \mathrm{~m}^{3}$ e $3 \mathrm{~kg}$. O lixo comum foi retirado de embarcações no Porto de Fortaleza com valores totais de $704,8 \mathrm{~m}^{3}$ e $12 \mathrm{~kg}$.

A relação entre os resíduos retirados de embarcação declarados em volume foi de 90,5 \% para 
o lixo comum, seguido de $8,35 \%$ de recicláveis e 1,16\% para os perigosos, já os dados declarados em massa, a relação foi de $80 \%$ de lixo comum e $20 \%$ para os recicláveis, sendo possível diagnosticar que os resíduos perigosos são declarados apenas em volume, visto que são retirados em bombonas ou outros recipientes de volume conhecido.

Portanto, do exposto podemos inferir que: o porto de Fortaleza não está equipado, com instalações especificadas, para receber correta e seguramente todos os tipos de resíduos de embarcações. Há uma autoclave, adquirida para a inertização dos resíduos contaminados (perigosos), que se encontra sem atividade à espera de licença de operação. Entretanto, em 2013, a equipe observou que a autoclave encontra-se totalmente destruído, com resíduos de construção em toda a sua dimensão.

É necessário adequar o porto a Lei dos resíduos sólidos no que concerne a gestão e gerenciamento de resíduos sólidos, onde deve ser observada a seguinte ordem de prioridade: não geração, redução, reutilização, reciclagem, tratamento dos resíduos sólidos e disposição final ambientalmente adequada dos rejeitos.

\section{EFLUENTES LÍQUIDOS}

Os problemas observados sobre os efluentes líquidos no porto inserem-se: na destinação de seus efluentes sanitários, na geração de água pluvial potencialmente contaminada, pela dispersão de material nas áreas de movimentação de granéis sólidos, e, nos sistemas de gestão de efluentes oleosos, como áreas de geração destes efluentes com tratamentos ineficientes.

\section{I EFLUENTES SANITÁRIOS}

Para efeito didático, apresentaremos o fluxograma referentes à gestão de efluentes líquidos no Porto de Fortaleza, destacando a origem, local de geração, direcionamento, tratamento e destinação final das diferentes tipologias de efluentes observadas no porto.

Fluxograma dos efluentes sanitários no porto de Fortaleza

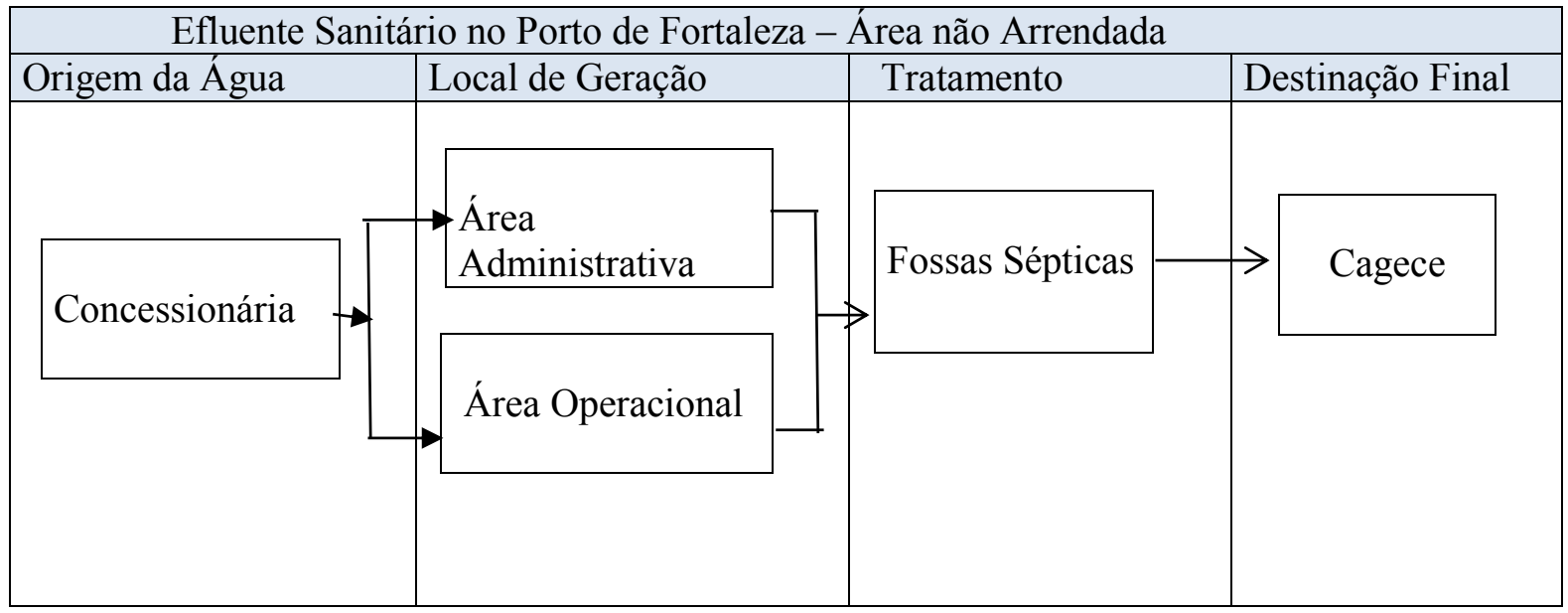

O fluxograma permiti-nos inferir que o porto não possui ligação com a rede de esgotamento sanitário do município, e não há tronco coletor de esgotamento próximo a área portuária. Portanto, todo o esgotamento do porto é direcionado a sistemas de fossas sépticas.

\section{I.I Água pluvial potencialmente contaminada}

A geração de água pluvial contaminada no porto ocorre, basicamente, em função das principais cargas movimentadas no porto, trigo, enxofre, coque, fertilizantes, da lavagem dos contêineres e de veículos de operação, e de manutenção de máquinas de refrigeração.

As áreas com potencial para geração de água pluvial contaminada, que foram demarcadas no Porto de Fortaleza, estão associadas a locais onde há acúmulo de resíduos no pátio e à área de lavagem 
de contêineres e de veículos de operação e de manutenção de máquinas. Essas áreas estão localizadas ao longo da esteira transportadora, próximas aos armazéns de carga a granel, ao cais do porto e ao pátio de contêineres e carga geral. No Pátio 6 é realizada a lavagem de contêineres que transportam cargas.

O Porto de Fortaleza não possui nenhum tanque de sedimentação instalado, toda a água que passa pelos sistemas de drenagem do porto é drenada diretamente para o mar.

No mapeamento apresentado a seguir, somente foram consideradas as áreas mais críticas onde há material espalhado pelo chão.

$\mathrm{Na}$ área localizada entre os armazéns 1 e 2, em parte dos perímetros 1 e 2, onde há movimentação de trigo. O granel alimentício é lançado diretamente do navio para a esteira aérea, no cais 2 , gerando resíduos durante a operação e também ao longo da esteira, do descarregamento até o local de armazenamento. Encontra-se, frequentemente, uma espessa camada de resíduos no piso, em uma área que ocupa, aproximadamente, 1000 metros. Em eventos de chuva esses resíduos podem ser carreados para a drenagem pluvial, e têm como destino a drenagem pluvial e, na sequência, o mar.

Nas áreas localizadas ao longo dos Perímetros 6, 8 e 9, encontra-se grande quantidade de granéis sólidos no piso e nas canaletas de drenagem pluvial. Devido à movimentação e transporte de materiais dispersivos como: sulfato de amônia, enxofre, coque etc. observa-se grande quantidade de resíduos dispersos no chão, proveniente do carregamento e descarregamento de caminhões. Caso chova, esse resíduo é carreado para a rede de drenagem pluvial, e tem como destino final o mar.

Já a área no Perímetro 6, corresponde ao local de lavagem de contêineres e de veículos de operação, no pátio de contêineres e carga geral. A lavagem ocorre em uma área inadequada e toda água proveniente dessa atividade é direcionada para a drenagem pluvial, chegando ao mar.

Fluxograma da água pluvial contaminada no porto de Fortaleza

\begin{tabular}{|c|c|c|c|}
\hline \multicolumn{4}{|c|}{ Água Pluvial Contaminada no Porto de Fortaleza - Área não arrendada } \\
\hline Origem da Água & Local de Geração & Direcionamento & Destinação \\
\hline Chuva & Área Operacional & $\begin{array}{l}\text { Captação pela rede de } \\
\text { drenagem }\end{array}$ & $\begin{array}{l}\text { Corpo } \\
\text { Hídrico }\end{array}$ \\
\hline
\end{tabular}

\section{I.2 Efluentes Oleosos}

Foram consideradas áreas críticas para efluentes oleosos os locais onde ocorre manutenção, abastecimento ou lavagem de maquinário. Nos casos apresentados estas áreas estão associadas a unidades ou sistemas de separação/acúmulo desses efluentes para posterior destinação, reuso ou descarte. Foram sugeridas medidas estruturais referentes ao tratamento de efluentes oleosos em áreas específicas do porto.

$\mathrm{Na}$ área (Perímetro 6), no pátio de contêineres e carga geral, são realizadas atividades de manutenção de maquinários. Os efluentes oleosos produzidos por essas atividades, geralmente, caem no pátio e são utilizados materiais absorventes apropriados para reter esse efluente e transformá-lo num resíduo sólido que é, posteriormente, armazenado em tambores, e assim é enviado para a matriz da própria empresa, situada fora da área portuária, e de lá para o seu destino final. O local não possui drenagem adequada e CSAO, requisitados para essas atividades exercidas. Em eventos de chuva o resíduo presente no pátio é carreado para a drenagem pluvial, e segue para o mar.

A área "B", localizada no Perímetro 11, representa a oficina de manutenção de maquinários, que possui CSAO e drenagem apropriada. Porém as estruturas dessa oficina não possuem manutenção adequada, apresentando quantidades de óleo armazenado maiores que os limites suportados pelas estruturas.

Os efluentes oleosos gerados nas embarcações e recebidos nos portos são classificados como resíduos sólidos, de acordo com a NBR 10.004/2004, e, portanto, eles estão comtemplados no universo de resíduos perigosos tratados em resíduos sólidos. Com relação aos efluentes sanitários oriundos de embarcações, não há evidências de estruturas para recepção destes no porto.

Sobre os resíduos perigosos, o Art. 37 da Lei dos Resíduos Sólidos oferece o seguinte enten- 
dimento:

A instalação e o funcionamento de empreendimento ou atividade que gere ou opere com resíduos perigosos somente podem ser autorizados ou licenciados pelas autoridades competentes se o responsável comprovar, no mínimo, capacidade técnica e econômica, além de condições para prover os cuidados necessários ao gerenciamento desses resíduos.

Fluxograma dos efluentes oleoso nas áreas arrendadas

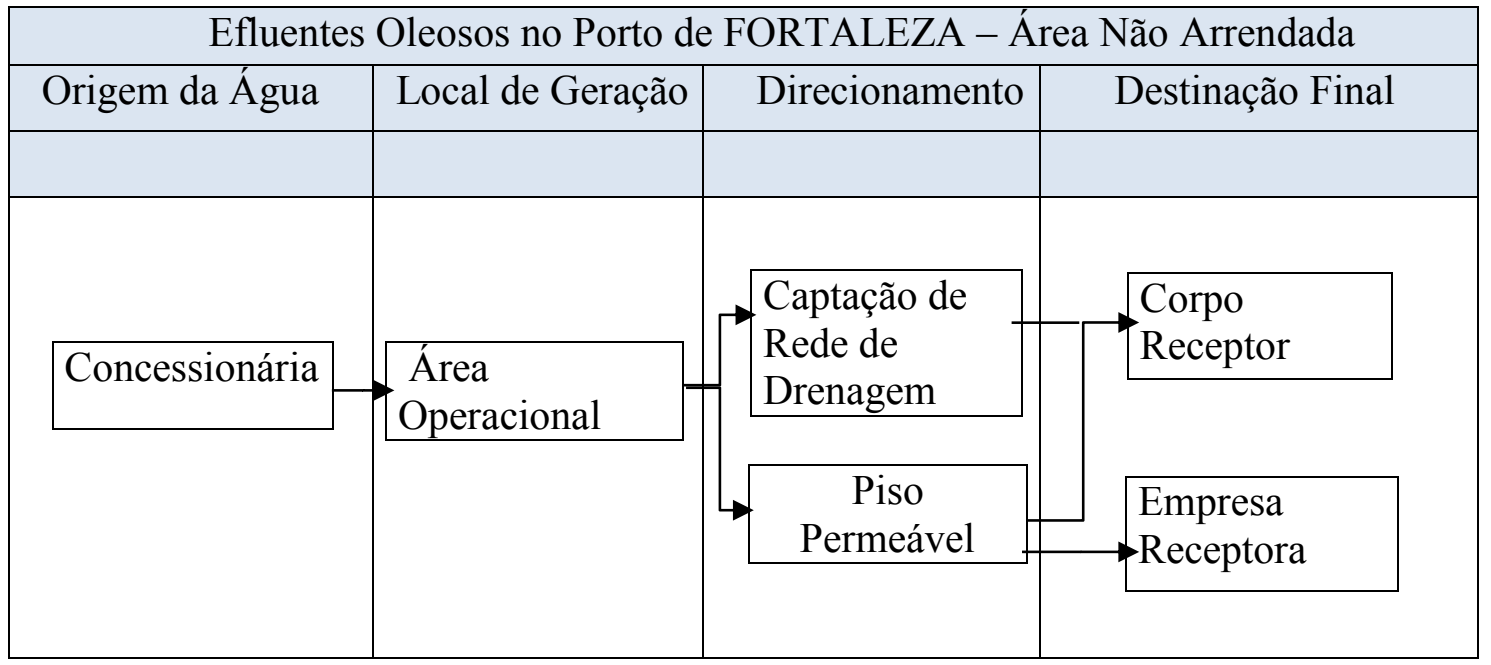

\section{FAUNA SINANTRÓPICA NOCIVA (FSN)}

No Porto de Fortaleza encontra-se um dos maiores pólos trigueiros do país e uma infraestrutura versátil que permite a movimentação de diferentes tipos de mercadorias, divididos em granéis sólidos (grãos, cereais, etc.), granéis líquidos derivados de petróleo, carga geral solta e conteinerizada. Muitas destas commodities constituem-se num atrativo para a FSN devido a algumas situações que acabam promovendo uma oferta abundante para sua alimentação.

A fase inicial do diagnóstico teve como metas angariar informações a respeito das ações tomadas para tratar da FSN, e também vistoriar as instalações do porto para saber em que situação elas se encontravam.

As instalações do Porto de Fortaleza apresentam várias adversidades de ordem estrutural. Muitas edificações possuem janelas quebradas, portões de galpões permanentemente abertos, caixas de ar condicionado inutilizadas, contêineres abandonados e cheios de entulhos e muitos vãos que permitem o abrigo e a nidificação das aves. Tais condições foram observadas inclusive em setores onde também existe a oferta de alimentos (silos e armazéns de grãos perecíveis). Outro problema de ordem estrutural diz respeito à ocorrência de irregularidades nos pisos e lajes, que prejudicam a drenagem e acarretam o acúmulo de águas pluviais e de resíduos dispersos decorrentes de movimentações de carga inadequadas.

O porto apresenta sucata acumulada em alguns locais, e foram observadas falhas nos procedimentos de armazenamento e movimentação de carga de granéis sólidos alimentícios. Estas circunstâncias promovem condições favoráveis à atração de espécies da FSN e são facilitadoras para a sua permanência.

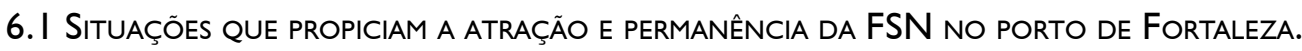

Entre as espécies de FSN diagnosticadas, as observadas e/ou capturadas foram: roedores (Rattus rattus e Rattus norvegicus), baratas (Periplaneta americana), moscas (Família Muscidae) e pombos (Columba livia). As quantidades observadas/capturadas de cada tipo de fauna estão apresentadas abaixo.

A distribuição destas espécies dentro do Porto de Fortaleza ficou conforme o explicitado a seguir:

Conforme constatação, os perímetros considerados como os mais problemáticos quanto à ocorrência de fauna sinantrópica nociva, apresentando as maiores quantidades de exemplares foi o P01 (Armazéns 01 e 02). 
Foram contabilizados 2.454 pombos. A área mais crítica foi o perímetro P01, que corresponde aos armazéns de trigo 1 e 2 . Mesmo os pombos domésticos sendo animais que possuem um grande nicho de atuação e tendo as áreas de entorno do porto os quatro fatores (4 As = abrigo, água, acesso e alimento) que favorecem a sua presença, estes fatores estão ainda em maior volume dentro da área portuária, explicando a grande população permanente de pombos observada nesta área.

Há concentrações menores, porém que também necessitam de manejo, nos perímetros P08 e P12, correspondentes aos Armazéns de Cargas Diversas 3 e 4, e ao Terminal Vecol/Depom, respectivamente. No primeiro local há oferta de alimento e áreas de abrigo para construção de ninhos. Já no segundo o problema é basicamente a disponibilidade de locais para pouso e reprodução.

\section{I.I Roedores}

No Porto de Fortaleza foram capturadas duas espécies de roedores típicos das zonas urbanas. De acordo com os cálculos da metodologia proposta, obteve-se um baixo índice de capturas de roedores. A amostragem teve maior êxito nos Armazéns 1 e 2 (P01) e no Pátio de Contêineres (P06), onde foram capturados respectivamente, três indivíduos de Rattus norvegicus e quatro indivíduos de Rattus rattus e dois de Rattus norvegicus. Muito embora a coleta de dados tenha demonstrado uma baixa densidade, observa-se ao longo do porto várias espécies de roedores mortos ao longo de todos os perímetros.

\subsubsection{Moscas}

As moscas diagnosticadas, de modo geral, tiveram sua identificação feita até a categoria taxonômica de família. Algumas amostras foram enviadas para especialistas da Universidade Federal Rural do Rio de Janeiro - UFRRJ, quando puderam ser identificadas até a categoria de espécie. Dentro do Porto de Fortaleza foram coletados 54 indivíduos da Família Muscidae, sendo 53 indivíduos no Cais 1 (P02) e um único individuo no perímetro onde está o Terminal CDA/Transpetro (P11).

Tais resultados demonstram que, dentro do Porto de Fortaleza, as populações de moscas se mostram em níveis de tolerância aceitáveis. Porém ações preventivas e corretivas para o controle geral das espécies de FSN devem ser aplicadas para que estes níveis se mantenham.

\section{I.3 Baratas}

A captura das baratas foi bastante prejudicada devido a problemas na isca das armadilhas utilizadas. Apesar disso foi constatada a presença desses insetos na área do porto. Com as armadilhas comerciais utilizadas foram coletados cinco indivíduos da espécie Periplaneta americana, divididas entre os perímetros P02 (Cais 1), P03 (CODINF e entrada de passageiros) e P06 (Pátio de Contêineres).

O número de baratas coletadas, se analisado isoladamente, leva à conclusão precipitada de uma presença de baratas em baixa quantidade no Porto de Fortaleza. Portanto, a avaliação foi feita utilizando dados de todas as visitas feitas ao porto, junto aos dados das coletas e às observações feitas durante as campanhas. Desta maneira foi possível constatar uma presença de uma quantidade desses insetos no porto que deve passar por ações de controle/manejo.

\section{CONCLUSÃO}

Conclui-se na necessidade urgente de um Plano de Gerenciamento estabelecido entre a autoridade portuária, autoridades intervenientes e os arrendatários no sentido de que os resíduos sólidos, efluentes líquidos e fauna sinantrópica nociva, verificado no Porto de Fortaleza, sejam devidamente minimizados possibilitando, dessa forma, uma gestão mais segura.

\section{REFERÊNCIAS}

ABNT - ASSOCIAÇÃO BRASILEIRA DE NORMAS TÉCNICAS. NBR 10.004 - Resíduos sólidos - Classificação. Rio de Janeiro, 2004.

BRASIL - LEI 12.305. Política Nacional de Resíduos Sólidos. Brasília, 2010. 